\title{
Preoperative cerebral hemodynamics from birth to surgery in neonates with critical congenital heart disease
}

Jennifer M. Lynch, MD, PhD, ${ }^{a}$ Tiffany Ko, MS, ${ }^{\text {b,c }}$ David R. Busch, PhD, ${ }^{\text {cd }}$ John J. Newland, BS, ${ }^{\text {d }}$ Madeline E. Winters, BS, ${ }^{\mathrm{d}}$ Kobina Mensah-Brown, BSE, ${ }^{\mathrm{d}}$ Timothy W. Boorady, BA, ${ }^{\mathrm{d}}$ Rui Xiao, PhD, ${ }^{\mathrm{e}}$ Susan C. Nicolson, MD, ${ }^{f}$ Lisa M. Montenegro, MD, ${ }^{\mathrm{f}}$ J. William Gaynor, MD,${ }^{\mathrm{g}}$ Thomas L. Spray, MD, ${ }^{\mathrm{g}}$ Arjun G. Yodh, PhD, ${ }^{\mathrm{c}}$ Maryam Y. Naim, MD, ${ }^{\mathrm{h}}$ and Daniel J. Licht, $\mathrm{MD}^{\mathrm{d}}$

\section{ABSTRACT}

Background: Hypoxic-ischemic white matter brain injury commonly occurs in neonates with critical congenital heart disease. Recent work has shown that longer time to surgery is associated with increased risk for this injury. In this study we investigated changes in perinatal cerebral hemodynamics during the transition from fetal to neonatal circulation to ascertain mechanisms that might underlie this risk.

Methods: Neonates with either transposition of the great arteries (TGA) or hypoplastic left heart syndrome (HLHS) were recruited for preoperative noninvasive optical monitoring of cerebral oxygen saturation, cerebral oxygen extraction fraction, and cerebral blood flow using diffuse optical spectroscopy and diffuse correlation spectroscopy, 2 noninvasive optical techniques. Measurements were acquired daily from day of consent until the morning of surgery. Temporal trends in these measured parameters during the preoperative period were assessed with a mixed effects model.

Results: Forty-eight neonates with TGA or HLHS were studied. Cerebral oxygen saturation was significantly and negatively correlated with time, and oxygen extraction fraction was significantly and positively correlated with time. Cerebral blood flow did not significantly change with time during the preoperative period.

Conclusions: In neonates with TGA or HLHS, increasing cerebral oxygen extraction combined with an abnormal cerebral blood flow response during the time between birth and heart surgery leads to a progressive decrease in cerebral tissue oxygenation The results support and help explain the physiological basis for recent studies that show longer time to surgery increases the risk of acquiring white matter injury. (J Thorac Cardiovasc Surg 2018;156:1657-64)

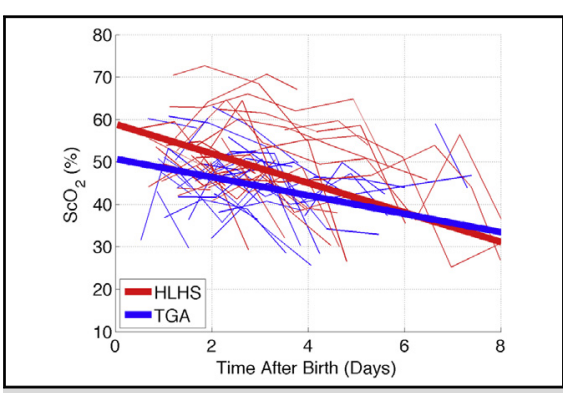

Cerebral oxygen saturation decreases preoperatively in neonates with HLHS and TGA.

\section{Central Message}

Cerebral oxygen extraction increases during the preoperative period in neonates with HLHS and TGA without a corresponding increase in oxygen delivery.

\section{Perspective}

A main focus of research on complex congenital heart disease is on modifiable risk factors for white matter injury. Recent work has shown that waiting longer for surgery might be the most significant risk factor. The findings reported herein show an imbalance between oxygen demand and delivery that increases as the child waits for surgery. This metabolic mismatch results in injury in the vulnerable brain.

See Editorial Commentary page 1665.

See Editorial page 1654.

\footnotetext{
From the Divisions of ${ }^{\mathrm{a}}$ General Pediatrics, ${ }^{\mathrm{d}}$ Neurology, ${ }^{\mathrm{f}}$ Cardiothoracic Anesthesia, ${ }^{\mathrm{g}}$ Cardiothoracic Surgery, and ${ }^{\mathrm{h}}$ Cardiac Critical Care Medicine, The Children's Hospital of Philadelphia, Philadelphia, $\mathrm{Pa}$; and Departments of ${ }^{\mathrm{b}}$ Bioengineering, ${ }^{\mathrm{c}}$ Physics and Astronomy, and ${ }^{\mathrm{e}}$ Biostatistics and Epidemiology, University of Pennsylvania, Philadelphia, Pa.

This study was supported by the National Institutes of Health grants NS-072338, NS60653, HL-007954, HL-007915, and P41-EB015893, the Thrasher Research Foundation, and the June and Steve Wolfson Family Foundation.

Received for publication May 22, 2017; revisions received April 19, 2018; accepted for publication April 24, 2018; available ahead of print May 30, 2018.

Address for reprints: Jennifer M. Lynch, MD, PhD, The Children's Hospital of Philadelphia, 3401 Civic Center Blvd, Philadelphia, PA 19104 (E-mail: lynchj3@ email.chop.edu)

$0022-5223 / \$ 36.00$

Copyright (c) 2018 by The American Association for Thoracic Surgery

https://doi.org/10.1016/j.jtcvs.2018.04.098
}

Approximately 30,000 children are born each year in the United States with congenital heart disease (CHD). Nearly one-third of these children are born with critical CHD, defined as lesions that require cardiac surgery in the neonatal period. ${ }^{1}$ In the past 3 decades, survival of neonates with CHD has improved dramatically, with most of

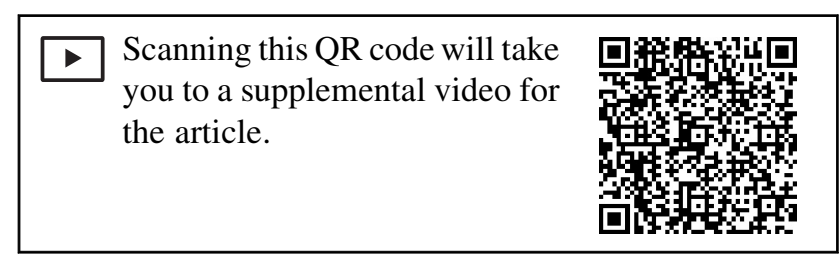




$\begin{aligned} & \text { Abbreviations and Acronyms } \\ & \mathrm{BFI}=\text { blood flow index } \\ & \mathrm{CaO}_{2}=\text { arterial oxygen concentration } \\ & \mathrm{CBF}=\text { cerebral blood flow } \\ & \mathrm{CHD}=\text { congenital heart disease } \\ & \mathrm{CMRO}_{2, \mathrm{i}}= \text { index of cerebral metabolic rate of } \\ & \text { oxygen consumption } \\ & \mathrm{CVR}=\text { cerebral vascular resistance } \\ & \mathrm{DCS}=\text { diffuse correlation spectroscopy } \\ & \mathrm{DOS}=\text { diffuse optical spectroscopy } \\ & \mathrm{Hb}=\text { deoxyhemoglobin, measured with } \\ & \text { diffuse optical spectroscopy } \\ & \mathrm{HbO}=\text { oxyhemoglobin, measured with diffuse } \\ & \text { optical spectroscopy } \\ & \mathrm{Hgb}=\text { hemoglobin, measured from blood gas } \\ & \mathrm{HLHS}=\text { hypoplastic left heart syndrome } \\ & \mathrm{MRI}=\text { magnetic resonance imaging } \\ & \mathrm{PVL}=\text { periventricular leukomalacia } \\ & \mathrm{OEF}=\text { cerebral oxygen extraction fraction } \\ & \mathrm{ScO}=\text { cerebral tissue oxygen saturation } \\ & \mathrm{SpO}=\text { peripheral oxygen saturation } \\ & \mathrm{TGA}=\text { transposition of the great arteries } \\ & \mathrm{WMI}=\text { white matter injury }\end{aligned}$

these patients now reaching school age. ${ }^{2}$ The focus of research has shifted from survival beyond the neonatal period to addressing the neurodevelopment disabilities seen among long-term survivors. Nearly half of the school-age survivors exhibit neurobehavioral symptoms, such as inattention, hyperactivity, and impaired executive function. ${ }^{3-5}$

Increasing evidence suggests that underlying these neurobehavioral symptoms is hypoxic-ischemic white matter injury (WMI) seen on brain magnetic resonance imaging (MRI) scans, termed periventricular leukomalacia (PVL). ${ }^{6-9} \mathrm{We}$ have previously reported that longer time between birth and surgery was associated with an increased risk for WMI/PVL in infants with transposition of the great arteries (TGA) and hypoplastic left heart syndrome (HLHS). ${ }^{10,11}$ Because of this common risk of increased time to surgery, the objective of this study was to investigate preoperative cerebral physiology and hemodynamics in neonates with HLHS and TGA to elucidate the pathology underlying the increased risk for brain injury with longer waiting times for surgery. Diffuse optical spectroscopy (DOS) and diffuse correlation spectroscopy (DCS) were used for noninvasive bedside quantification of preoperative cerebral hemodynamics, ${ }^{12,13}$ and the time course of these parameters during the preoperative period.

\section{METHODS \\ Patient Population}

All term (37-42 weeks gestation) newborns with pre- or postnatally diagnosed critical CHD admitted to the cardiac intensive care unit at the Children's Hospital of Philadelphia were screened for study inclusion and approached for participation as early as possible. Exclusion criteria included: birth weight $<2 \mathrm{~kg}$, a history of neonatal depression (eg, 5-minute APGAR $<5$, cord blood $\mathrm{pH}<7.0$, sepsis, or birth asphyxia), perinatal seizures, evidence of end-organ injury, preoperative cardiac arrest, and significant preoperative intracerebral hemorrhage such as grade 3 or 4 intraventricular hemorrhage. Infants with identified or suspected genetic syndromes were not excluded.

\section{Study Protocol}

All procedures were approved by the institutional review board at the Children's Hospital of Philadelphia. Patient demographic data were recorded. Daily DOS/DCS measurements of cerebral tissue oxygen saturation $\left(\mathrm{ScO}_{2}\right)$, cerebral oxygen extraction fraction (OEF), and cerebral blood flow (CBF) were made as soon as consent was obtained, with the last measurement made on the morning of surgery before induction of anesthesia. Vitals data were captured continuously (CNS Technology, LLC, Ambler, Penn), and daily measurements of peripheral oxygen saturation $\left(\mathrm{SpO}_{2}\right)$ from pulse oximetry are reported from the time that the daily DOS/DCS measurements were performed. Preoperative blood gases were acquired per clinical protocol, and arterial hemoglobin (Hgb) concentration on day of birth and day of surgery are reported.

\section{DOS/DCS Measurements}

DOS and DCS use near-infrared light to noninvasively probe the static and dynamic properties of cortical brain tissue. Our custom-made optical instrument combines these 2 techniques on a mobile cart that can be used in the MRI suite, the operating room, and perioperatively at the bedside (Video 1). ${ }^{14-16}$

DOS (also known as frequency-domain near-infrared spectroscopy) is a widely accepted method to quantify tissue oxygenation. Multiseparation frequency domain DOS, used in this study, is capable of accurate quantification of $\mathrm{ScO}_{2}$ (ie, in contrast to commercial oximeters that use continuouswave near-infrared spectroscopy to monitor trends in cerebral oxygen saturation). ${ }^{17-19}$ DOS uses photon diffusion theory to relate the measured amplitude attenuation and phase shift of modulated and multiply scattered light detected on the tissue surface to the wavelengthdependent tissue absorption $\left(\mu_{a}\right)$ and scattering $\left(\mu_{s}\right)$ properties. The wavelength and time-dependent absorption coefficient, $\mu_{a}(\lambda, t)$, depends linearly on oxyhemoglobin $\left(\mathrm{HbO}_{2}\right)$ and deoxyhemoglobin $(\mathrm{Hb})$ concentration; thus measurements at multiple wavelengths yields these 2 parameters. From $\mathrm{HbO}_{2}$ and $\mathrm{Hb}$, we derive total $\mathrm{Hgb}$ concentration $\left(\mathrm{THC}=\mathrm{HbO}_{2}+\mathrm{Hb}\right)$ and $\mathrm{ScO}_{2}\left(\mathrm{ScO}_{2}=\mathrm{HbO}_{2} / \mathrm{THC}\right)$. OEF can be calculated from $\mathrm{ScO}_{2}$ and $\mathrm{SpO}_{2}$ measured clinically from a pulse-oximeter using the formula $O E F=\frac{1}{\gamma} \frac{S p O_{2}-S_{2} O_{2}}{\mathrm{SpO}_{2}}$, where $\gamma$ is the fraction of blood in the venous compartment, assumed to be $0.75 .{ }^{14,20}$ Cerebral blood volume $(\mathrm{mL} / 100 \mathrm{~g}$ of tissue) can be calculated from THC. The DOS device used in the present study (Imagent, ISS Inc, Champaign, Ill) is amplitude modulated at $110 \mathrm{MHz}$ and uses source lasers at 2 wavelengths, $\lambda=688$ and $830 \mathrm{~nm}$.

DCS uses near-infrared light to noninvasively monitor CBF. DCS measures the temporal fluctuations of the light intensity emerging in remission at the tissue surface; these fluctuations are caused primarily by moving red blood cells. ${ }^{12,21-25}$ Correlation diffusion theory is then used to convert these temporal fluctuations into a blood flow index (BFI; measured in units of $\left.\mathrm{cm}^{2} / \mathrm{s}\right) .{ }^{12}$ Although this index does not have traditional physiological units of $\mathrm{CBF}$, recent studies have shown that BFI correlates strongly with other gold standard measures of CBF. ${ }^{15,16,26-30}$ Specifically, Jain et al validated BFI against CBF measured in the superior sagittal sinus with phase 


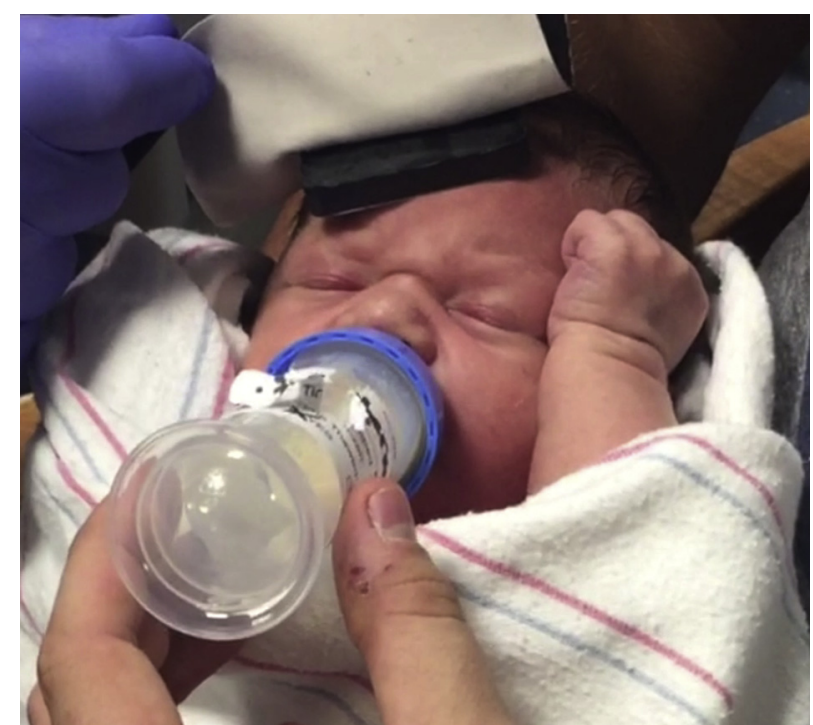

VIDEO 1. Demonstration of optical measurements of cerebral blood flow and oxygen saturation. Video available at: https://www.jtcvs.org/article/ S0022-5223(18)31237-6/fulltext.

contrast MRI in a similar population of infants with critical CHD. ${ }^{16}$ Further, BFI can be combined with OEF, calculated using the equation above to give an index of cerebral metabolic rate of oxygen consumption $\left(\mathrm{CMRO}_{2, i}\right)$ using the formula: $C M R O_{2, i}=O E F \times B F I \times C a O_{2}$, where $\mathrm{CaO}_{2}$ is the arterial oxygen concentration, which can be approximated as $\mathrm{CaO}_{2} \approx 1.39 \times \mathrm{SpO}_{2} \times \mathrm{Hgb}^{14,15}$

DOS and DCS measurements were conducted once daily from the day of consent until the morning of surgery. The time of the measurements was recorded with respect to the subject's time of birth. Measurements were made noninvasively over the right as well as left frontal cortex. At each location, 4 repetitions of the basic measurement were acquired to account for local inhomogeneities under the optical probe. These 8 repetitions were then averaged to derive a global measure of $\mathrm{ScO}_{2}$ and $\mathrm{BFI}$.

\section{Brain MRI}

In a subset of patients $(\mathrm{n}=33)$, a brain MRI scan was obtained immediately before surgery as part of a different study protocol. ${ }^{11,16}$ All images were acquired using a 1.5T Avanto MRI system (Siemens Medical Systems, Malvern, Penn) using a 12-channel head coil. The studies included T1-weighted magnetization-prepared rapid acquisition gradient echo and T2-weighted sampling perfection with application-optimized contrasts using different flip angle evolution sequences acquired in the axial plane. Two independent observers, who were unaware of the clinical data, evaluated the total brain maturation score using axial T1- and T2-weighted images. ${ }^{31,32}$

\section{Statistical Analysis}

For analysis purposes, patients were grouped according to cardiac diagnosis. Continuous variables were summarized using standard descriptive statistics (mean and SD, or median and interquartile range as appropriate), and frequencies and percentages were used for categorical variables.

The preoperative temporal trends in cerebral hemodynamics were examined using a linear mixed effects model implemented within the SAS mixed procedure, a method commonly used for analyzing correlated data such as repeated measures or clustered data. The model was used to predict the mean outcome variable (ie, $\mathrm{ScO}_{2}, \mathrm{OEF}, \mathrm{BFI}, \mathrm{CMRO}_{2, \mathrm{i}}$, and $\mathrm{SpO}_{2}$ ) as a function of time and cardiac diagnosis. In this study, because a single measurement was taken on the same patient at multiple time points, these measures (ie, $\mathrm{ScO}_{2}$, $\mathrm{OEF}, \mathrm{BFI}, \mathrm{CMRO}_{2, \mathrm{i}}$, and $\mathrm{SpO}_{2}$ ) are correlated with each other; we refer to this as "within-subject correlation." Specifically, subject-specific random effects were included in the model to account for within-subject correlations resulting from the repeated measures. Random intercept and slope were assumed in the linear mixed-effects model to capture potential difference in the baselines and trajectories among individuals. For the covariance structure, we compared the compound symmetry with the autoregressive (1), and we used the Akaike information criterion to determine the optimal covariance matrices. Compound symmetry assumes that correlations between all pairs of measures within the same subject are the same, whereas autoregressive (1) assumes that correlations between 2 measures decrease exponentially with distance (ie, decrease with the time between the 2 measures). Normality of the outcome variables was examined graphically and statistically using Shapiro-Wilk test. In the mixed effects model, we considered linear as well as nonlinear temporal trends by including a term quadratic in time into the model. All analyses were performed using SAS version 9.4 statistical software (SAS Institute Inc, Cary, NC). Statistical significance was declared for $P$ values $<.05$.

\section{RESULTS}

From March 2013 to March 2016, a total of 70 neonates with complex CHD were recruited. Cardiac diagnoses included HLHS $(n=24)$, TGA $(n=24)$, tetralogy of Fallot $(n=6)$, hypoplastic arch $(n=3)$, interrupted aortic arch $(\mathrm{n}=3)$, aortic atresia $(\mathrm{n}=3)$, double inlet left ventricle $(\mathrm{n}=2)$, truncus arteriosis $(\mathrm{n}=2)$, coarctation of the aorta $(\mathrm{n}=2)$, and double outlet right ventricle $(\mathrm{n}=1)$. Because of challenges in grouping patients with shared physiology, and small numbers in certain groups, our analysis was limited to only patients with TGA and HLHS.

Patient demographic characteristics for the subset of patients with TGA or HLHS $(\mathrm{n}=48)$ are summarized in Table 1. All patients were full-term with an average gestational age of $38.9 \pm 0.7$ weeks and an average time to surgery of $4.3 \pm 2.5$ days. In this cohort, patients with a diagnosis of TGA had on average an older gestational age than those with a diagnosis of HLHS. No differences in birth weight, time to surgery, head circumference, or brain maturation were observed between diagnoses.

Initial measurements of $\mathrm{ScO}_{2}, \mathrm{OEF}, \mathrm{BFI}$, and $\mathrm{CMRO}_{2, \mathrm{i}}$ are reported in Table 1. The first measured $\mathrm{ScO}_{2}$ was lower on average $(P=.04)$ in patients with TGA $(46.8 \pm 8.9 \%)$ compared with patients with HLHS $(52.0 \pm 7.2 \%)$. The average initial $\mathrm{ScO}_{2}$ among all subjects was $49.4 \pm 8.4 \%$. Daily measurements of $\mathrm{ScO}_{2}$, OEF, BFI, and $\mathrm{CMRO}_{2, \mathrm{i}}$ for all subjects are shown in Figure 1. Preoperative measurements of $\mathrm{Hgb}$ and daily measurements of $\mathrm{SpO}_{2}$ are shown in Figure 2.

We performed a linear mixed effects model to assess the effects of time and cardiac diagnosis on the daily measurements of $\mathrm{ScO}_{2}, \mathrm{OEF}, \mathrm{BFI}$, and $\mathrm{CMRO}_{2, \mathrm{i}}$ (Table 2, Figure 1) and on daily measurements of $\mathrm{SpO}_{2}$ (Table 3, Figure 2). Because preoperative $\mathrm{ScO}_{2}$ was different between the 2 cohorts, cardiac diagnosis was included in the mixed effects model as a covariate. Only the results from a linear model are reported because higher order 
TABLE 1. Patient demographic characteristics and initial optical measurements

\begin{tabular}{|c|c|c|c|c|}
\hline & All $(n=48)$ & HLHS $(n=24)$ & TGA $(n=24)$ & $P$ value \\
\hline \multicolumn{5}{|l|}{ Demographic characteristics } \\
\hline Female, n $(\%)$ & $17(35.4)$ & $9(37.5)$ & $8(33.3)$ & .76 \\
\hline Time to surgery, $\mathrm{d}$ & $4.3 \pm 2.5$ & $4.8 \pm 3.0$ & $3.9 \pm 1.7$ & .42 \\
\hline Gestational age, wk & $38.9 \pm 0.7$ & $39.2 \pm 0.7$ & $38.7 \pm 0.6$ & .03 \\
\hline Birth weight, kg & $3.4 \pm 0.5$ & $3.5 \pm 0.4$ & $3.3 \pm 0.5$ & .31 \\
\hline Head circumference, $\mathrm{cm}$ & $34.3 \pm 1.6$ & $34.5 \pm 1.2$ & $34.1 \pm 1.9$ & .18 \\
\hline Total Brain Maturation Score* & $10.2 \pm 1.1$ & $10.0 \pm 1.2$ & $10.5 \pm 1.0$ & .23 \\
\hline \multicolumn{5}{|l|}{ Optical measurements } \\
\hline Number of measurements & $4.0 \pm 2.4$ & $4.6 \pm 3.1$ & $3.3 \pm 1.3$ & .12 \\
\hline Initial $\mathrm{ScO}_{2}, \%$ & $49.4 \pm 8.4$ & $52.0 \pm 7.2$ & $46.8 \pm 8.9$ & .04 \\
\hline Initial OEF & $0.59 \pm 0.13$ & $0.57 \pm 0.11$ & $0.62 \pm 0.15$ & .20 \\
\hline Initial BFI $\left(10^{-8} \mathrm{~cm}^{2} / \mathrm{s}\right)$ & $1.7 \pm 0.7$ & $1.5 \pm 0.6$ & $1.9 \pm 0.7$ & .07 \\
\hline Initial $\mathrm{CMRO}_{2, \mathrm{i}}\left(10^{-7} \mathrm{~mL} / \mathrm{dL} \times \mathrm{cm}^{2} / \mathrm{s}\right)$ & $1.9 \pm 0.9$ & $1.7 \pm 0.9$ & $2.1 \pm 0.9$ & .10 \\
\hline
\end{tabular}

$H L H S$, Hypoplastic left heart syndrome; $T G A$, transposition of the great arteries; $\mathrm{ScO}_{2}$, cerebral tissue oxygen saturation; $\mathrm{OEF}$, oxygen extraction fraction; $B F I$, blood flow index; $\mathrm{CMRO}_{2, i}$, cerebral metabolic rate of oxygenation. *Total Brain Maturation Score measured only for a subset of patients (HLHS: $\mathrm{n}=20 ;$ TGA: $\mathrm{n}=13$ ).

of effects of time were not found to be significant. Time from birth was a significant predictor of preoperative $\mathrm{ScO}_{2}(P=.02)$, and $\mathrm{OEF}(P=.01)$. Cardiac diagnosis (HLHS or TGA) significantly predicts preoperative $\mathrm{ScO}_{2}(P<.01)$, BFI $(P=.05)$, and $\mathrm{SpO}_{2}(P=.01)$. The interaction between cardiac diagnosis and time was not a significant predictor of any of the outcome variables. We also performed a linear mixed-effects model on the subset $(n=33)$ of subjects who received brain MRI scans on the morning of surgery to assess the effect of brain maturation on preoperative $\mathrm{CMRO}_{2, \mathrm{i}}$ (Table 4); the latter was computed using a simple steady-state model described in the Methods section. Total brain maturation score did not affect the temporal trends of $\mathrm{CMRO}_{2, \mathrm{i}}$ but was inversely related to baseline measurements of $\mathrm{CMRO}_{2, \mathrm{i}}(P=.03)$.
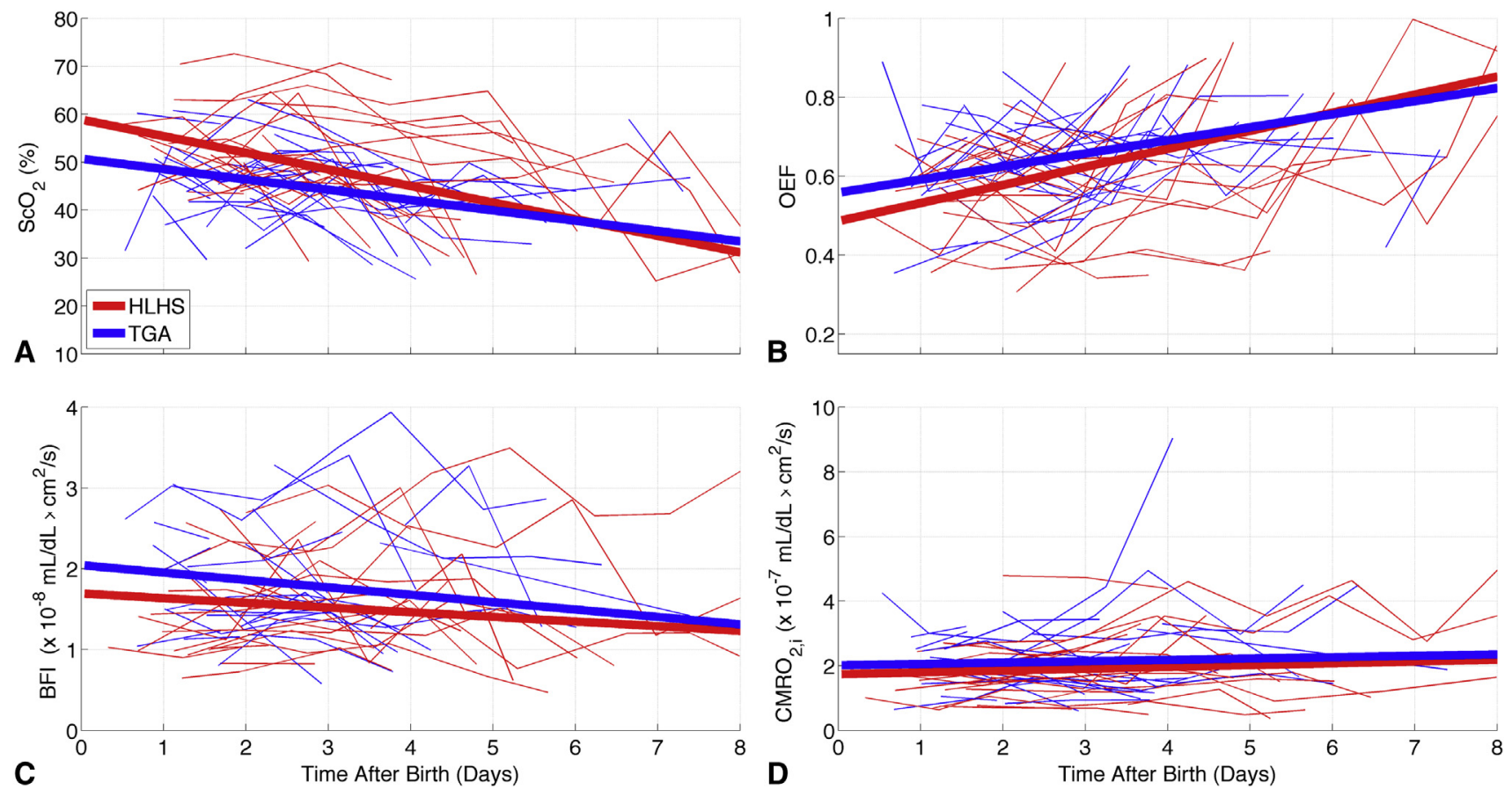

FIGURE 1. Time profiles of $\mathrm{ScO}_{2}(\mathrm{~A}), \mathrm{OEF}(\mathrm{B}), \mathrm{BFI}(\mathrm{C})$, and $\mathrm{CMRO}_{2, \mathrm{i}}(\mathrm{D})$. Each thin line represents measurements for a single subject with either hypoplastic left heart syndrome ( $r e d$ ) or transposition of the great arteries (blue). Thick lines represent linear trends derived from a mixed effects model reported in Table 2. $\mathrm{ScO}_{2}$, Cerebral tissue oxygen saturation; $H L H S$, hypoplastic left heart syndrome; $T G A$, transposition of the great arteries; $O E F$, cerebral oxygen extraction fraction; $\mathrm{BFI}$, blood flow index; $\mathrm{CMRO}_{2, i}$, index of cerebral metabolic rate of oxygen consumption. 

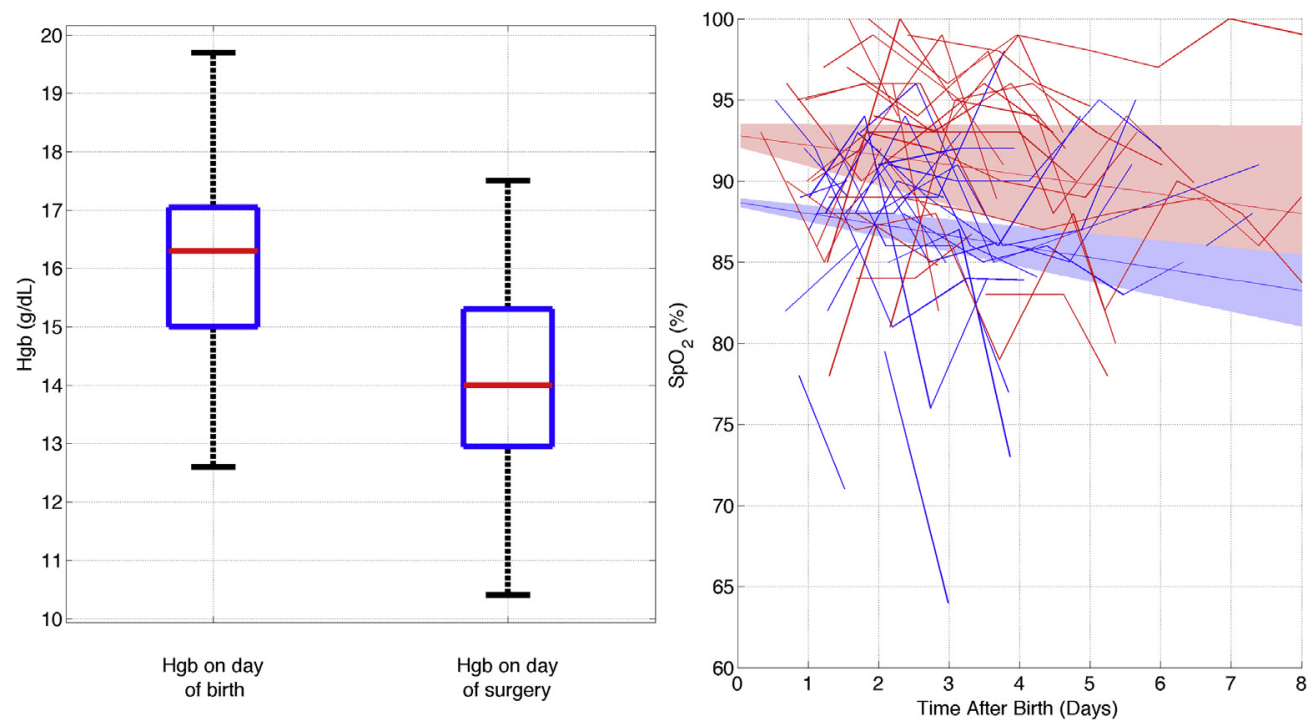

FIGURE 2. Left: box plot showing preoperative hemoglobin on day of birth and on day of surgery. Right: time profiles of $\mathrm{SpO}_{2}$. Each thin line represents measurements for a single subject with either a hypoplastic left heart syndrome (red) or transposition of the great arteries (blue). Thick lines represent linear trends derived from a mixed effects model reported in Table 3 and shaded area represents the $95 \%$ confidence interval of the model. $H g b$, hemoglobin, measured from blood gas; $\mathrm{SpO}_{2}$, peripheral capillary oxygen saturation.

\section{DISCUSSION}

This investigation is, to our knowledge, the first to report on longitudinal monitoring of preoperative cerebral hemodynamics in neonates with critical CHD. Previous studies have independently investigated cross-sectional trends in preoperative saturations in these 2 patient populations. ${ }^{10,11}$ Our group previously used the same noninvasive optical techniques (DOS/DCS) to measure $\mathrm{ScO}_{2}$ immediately before surgery in infants with HLHS. ${ }^{11}$ In our crosssectional analysis, preoperative $\mathrm{ScO}_{2}$ was negatively correlated with a longer time between birth and surgery, suggesting that $\mathrm{ScO}_{2}$ decreases between birth and surgery. This initial observation is further supported by the present study because daily measurements of preoperative $\mathrm{ScO}_{2}$ were found to negatively correlate with time. In the previous $^{11}$ as well as current study, the differences in timing of surgery between subjects were a result of "modifiable" logistics including availability of the requested surgeon and the day of the week on which the patient was born. No patients went to surgery early (eg, for pulmonary overcirculation) or had surgery delayed for medical reasons (eg, for infection, bleeding, seizures).

Although preoperative cerebral hemodynamics have been previously studied using DOS/DCS in neonates with TGA, the relationship to time to surgery has not been previously investigated. In 2009, Petit et al reported that preoperative brain injury in neonates with TGA was associated with systemic hypoxemia and longer time to surgery, again suggesting that increased risk of WMI/PVL with longer time to surgery could be due to decreasing $\mathrm{ScO}_{2}$ during the preoperative period. ${ }^{10}$ With the present study we were able to confirm this finding and were able to show longitudinal decrease in $\mathrm{ScO}_{2}$ similar to the decreases in $\mathrm{ScO}_{2}$ measured in neonates with HLHS. Because the increase in preoperative oxygen extraction exists independent of cardiac diagnosis, our findings suggest a commonality in the mechanism behind the previously reported increased risk for WMI/PVL with longer time to surgery in both populations.

The decreases in $\mathrm{ScO}_{2}$ measured in this patient population are larger in magnitude than what would be expected for a healthy neonate. Franceschini et al similarly used DOS to study trends in $\mathrm{ScO}_{2}$ in healthy infants over the first year of life. ${ }^{33}$ They reported an average decrease of 10 percentage points in $\mathrm{ScO}_{2}$ from 0 to 6 weeks, without corresponding changes in cerebral blood volume or cerebral metabolic rate of oxygenation (this change was attributed to the decrease in hematocrit during the transition from fetal to adult $\mathrm{Hgb}$ ). This relatively minimal change in $\mathrm{ScO}_{2}$ is not sufficient to explain the large decrease in $\mathrm{ScO}_{2}$ of $-2.2 \%$ per day observed in this CHD population. Additionally, Franceschini et al reported an average $\mathrm{ScO}_{2}$ of $67 \%$ in healthy neonates measured during the first week of life, whereas the average initial $\mathrm{ScO}_{2}$ measured in this cohort of infants with CHD is $49.4 \pm 8.4 \%$. Therefore, it appears that infants with complex CHD are born with a lower than normal $\mathrm{ScO}_{2}$ and also experience a greater than normal decrease in saturation during the first week of life.

Cerebral oxygen extraction is related to oxygen delivery and metabolism through the equation: $C M R O_{2, i}=O E F \times B F I \times C a O_{2}$, valid in steady state, where $\mathrm{CaO}_{2}$ can be approximated as $\mathrm{CaO}_{2} \approx 1.39 \times$ 
TABLE 2. Coefficients and SE of the linear mixed effects model for the optically derived outcome variables $\mathrm{ScO}_{2}, \mathrm{OEF}$, BFI, and $\mathrm{CMRO}_{2, \mathrm{i}}$

\begin{tabular}{|c|c|c|}
\hline Outcome variable & $\begin{array}{c}\text { Estimate }(\mathrm{SE}) \text { of } \\
\text { coefficient }\end{array}$ & $P$ value \\
\hline \multicolumn{3}{|l|}{$\mathrm{ScO}_{2}, \%$} \\
\hline Intercept & $50.7(2.2)$ & $<.0001$ \\
\hline Time, $\mathrm{h}$ & $-0.09(0.04)$ & .02 \\
\hline Cardiac Dx & $8.2(2.8)$ & $<.01$ \\
\hline Time $\times$ Cardiac Dx & $-0.05(0.05)$ & .24 \\
\hline \multicolumn{3}{|l|}{ OEF } \\
\hline Intercept & $0.56(0.03)$ & $<.0001$ \\
\hline Time, h & $0.0014(0.0005)$ & .01 \\
\hline Cardiac Dx & $-0.07(0.04)$ & .09 \\
\hline Time $\times$ Cardiac Dx & $0.0005(0.0007)$ & .45 \\
\hline \multicolumn{3}{|l|}{ BFI, $10^{-8} \mathrm{~cm}^{2} / \mathrm{s}$} \\
\hline Intercept & $2.0(0.1)$ & $<.0001$ \\
\hline Time, h & $-0.003(0.003)$ & .16 \\
\hline Cardiac Dx & $-0.35(0.18)$ & .05 \\
\hline Time $\times$ Cardiac Dx & $0.001(0.003)$ & .69 \\
\hline \multicolumn{3}{|c|}{$\mathrm{CMRO}_{2, \mathrm{i}}, 10^{-7} \mathrm{~mL} / \mathrm{dL} \times \mathrm{cm}^{2} / \mathrm{s}$} \\
\hline Intercept & $2.0(0.2)$ & $<.0001$ \\
\hline Time, h & $0.002(0.004)$ & .68 \\
\hline Cardiac Dx & $-0.28(0.27)$ & .30 \\
\hline Time $\times$ Cardiac Dx & $0.0006(0.006)$ & .91 \\
\hline
\end{tabular}

For each outcome variable, the table reports the $y$-intercept for the linear model as well as the coefficients for the 3 variables: time after birth, cardiac diagnosis (HLHS and TGA), and an interaction term between diagnosis and time. For cardiac diagnosis, TGA was used as the reference group. The linear model for each outcome variable is $y=\beta_{0}+\beta_{1} \times$ Time $+\beta_{2} \times$ Cardiac Diagnosis $+\beta_{3} \times$ Time $\times$ Cardiac Diagnosis. $S E$, Standard error; $\mathrm{SCO}_{2}$, cerebral tissue oxygen saturation; $D x$, diagnosis; $O E F$, cerebral oxygen extraction fraction; $B F I$, blood flow index; $C M R O_{2, i}$, index of cerebral metabolic rate of oxygen consumption.

$\mathrm{SpO}_{2} \times \mathrm{Hgb}^{14,15}$ Therefore, an increase in OEF could be caused by an increase in $\mathrm{CMRO}_{2, \mathrm{i}}$, a decrease in BFI, a decrease in $\mathrm{SpO}_{2}$, a decrease in $\mathrm{Hgb}$, or a combination of these factors. In this study, it is reasonable to speculate that the observed increase in OEF after birth is due to a decrease in oxygen carrying capacity caused by decreased $\mathrm{Hgb}$ after repeated blood draws. However, we did not observe a statistically significant difference between $\mathrm{Hgb}$ measured on day of birth and Hgb measured on the day of

TABLE 3. Coefficients and SE of the linear mixed-effects model for the clinically derived outcome variable $\mathrm{SpO}_{2}$

\begin{tabular}{lcc}
\hline \multicolumn{1}{c}{ Outcome variable } & Estimate $(\mathrm{SE})$ of coefficient & $\boldsymbol{P}$ value \\
\hline $\mathrm{SpO}_{2}, \%$ & & \\
$\mathrm{Intercept}$ & $88.7(1.2)$ & $<.0001$ \\
Time, $\mathrm{h}$ & $-0.03(0.02)$ & .19 \\
Cardiac $\mathrm{Dx}$ & $4.1(1.6)$ & .01 \\
Time $\times$ Cardiac $\mathrm{Dx}$ & $0.003(0.029)$ & .91 \\
\hline
\end{tabular}

The table reports the $y$-intercept for the linear model as well as the coefficients for the 3 variables: time after birth, cardiac diagnosis (HLHS and TGA), and an interaction term between diagnosis and time. For cardiac diagnosis, TGA was used as the reference group. The linear model for each outcome variable is $y=\beta_{0}+\beta_{1} \times$ Time $+\beta_{2} \times$ Cardiac Diagnosis $+\beta_{3} \times$ Time $\times$ Cardiac Diagnosis. $S E$, Standard error; $\mathrm{SpO}_{2}$, peripheral capillary oxygen saturation; $D x$, diagnosis.
TABLE 4. Coefficients and SE from the linear mixed-effect model using time after birth, cardiac diagnosis (HLHS and TGA), TMS, and an interaction term between TMS and time as predictors for optically derived $\mathrm{CMRO}_{2, \mathrm{i}}$ on a subset of patients who received a preoperative brain MRI scan $(\mathbf{n}=33)$

\begin{tabular}{lcc}
\hline Outcome variable & Estimate (SE) of coefficient & $\boldsymbol{P}$ value \\
\hline $\mathrm{CMRO}_{2, \mathrm{i}}, 10^{-7}$ & & \\
$\mathrm{~mL} / \mathrm{dL} \times \mathrm{cm}^{2} / \mathrm{s}$ & & \\
Intercept & $5.1(1.2)$ & $<.0001$ \\
Time, $\mathrm{h}$ & $-0.01(0.03)$ & .61 \\
$\mathrm{Cardiac} \mathrm{Dx}$ & $-0.75(0.23)$ & $<.01$ \\
TMS & $-0.25(0.11)$ & .03 \\
Time $\times$ TMS & $0.001(0.003)$ & .62 \\
\hline
\end{tabular}

For cardiac diagnosis, TGA was used as the reference group. The linear model for each outcome variable is $y=\beta_{0}+\beta_{1} \times$ Time $+\beta_{2} \times$ Cardiac Diagnosis + $\beta_{3} \times T M S+\beta_{4} \times$ Time $\times T M S$. SE, Standard error; $\mathrm{CMRO}_{2, i}$, index of cerebral metabolic rate of oxygen consumption; $D x$, diagnosis; TMS, total brain maturation score.

surgery (Figure 2). A decrease in arterial oxygen saturation would also explain an increase in oxygen extraction, but we did not observe a decrease in $\mathrm{SpO}_{2}$ during the preoperative period. Furthermore, the expected physiological response to a decrease in oxygen-carrying capacity caused by a decrease in $\mathrm{Hgb}$, would be to increase $\mathrm{CBF}$ to keep oxygen supply constant; CBF did not exhibit this increase in our mixed effects model results from the whole study population. This absence of CBF compensation suggests a failure of compensatory mechanisms, for example a failure of cerebrovascular resistance. Further, the mismatch between increased oxygen extraction and stagnant oxygen delivery explains the association of longer time to surgery with increased risk for WMI/PVL before surgery in TGA and after surgery in HLHS.

Another possible cause for increased oxygen extraction during the preoperative period is an increased oxygen demand during the newborn period. However, $\mathrm{CMRO}_{2, \mathrm{i}}$ was not found to be increasing within error in this study. Previously, cerebral metabolic rate of oxygenation has been shown to increase during the first few weeks of life in premature infants with brain maturation similar to full-term infants with complex CHD. ${ }^{32,34}$ In the present study baseline $\mathrm{CMRO}_{2, \mathrm{i}}$ was found to be inversely related to brain maturation, thus supporting previous research that suggests brain immaturity is correlated with cerebral oxygen metabolism. ${ }^{34}$ An increase in oxygen demand would be expected to cause a corresponding increase in oxygen delivery, but again an increase in CBF was not observed indicating a failure of compensatory mechanisms.

Understanding the fetal circulation is salient to understanding the failure of $\mathrm{CBF}$ compensation to meet increasing preoperative oxygen extraction. Prenatal studies using Doppler ultrasound have shown fetuses with HLHS have lower than normal cerebral vascular resistance (CVR) ${ }^{35,36}$ Lower fetal CVR is likely due to decreased oxygen delivery to the brain caused by the altered 
anatomy that results from ductal-dependent $\mathrm{CBF}^{35,37}$ Doppler ultrasound in fetuses with TGA also shows a decrease in fetal CVR, reflecting a deficit in oxygen delivery that is due to the lower oxygen saturations caused by the transposed great vessels. ${ }^{37,38}$ Sustained decrease in CVR during fetal life could exhaust the compensatory mechanisms that are needed to increase $\mathrm{CBF}$ in response to increasing OEF.

The significance of longer time to surgery has been previously shown. ${ }^{10,11,39}$ Further, we have shown that in patients with HLHS there exists a strong correlation between lower cerebral oxygen saturation and longer time to surgery and that these factors increased the risk for the prevalence as well as severity of WMI/PVL. The current results provide insight into the underlying cause of this increased risk. These findings demonstrate the critical role of the preoperative period in the development of risk for $\mathrm{WMI} / \mathrm{PVL}$. If further corroborated, these observations could lead to a shift in the emphasis of neuroprotective strategies from the operative period to the preoperative period. However, because both of the aforementioned studies were conducted at a single center, it is imperative to investigate the preoperative period and risk for WMI/ PVL with age at time of Norwood procedure at different centers with different perioperative and operative clinical care strategies. A larger, multicenter study between the Children's Hospital of Philadelphia and Texas Children's Hospital is currently being pursued to further investigate the changing cerebral hemodynamics during the preoperative period and the effect on risk for WMI.

\section{Study Limitation}

A significant limitation of the present study was that measurements of preoperative cerebral hemodynamics were taken only once per day starting with the day of study inclusion when consent was obtained. Thus, the timing of the first measurement differed between subjects. Furthermore, measurements were performed at times of convenience rather than standardized to time of day. Because of this relatively low frequency of data acquisition, analysis with a mixed effects model was limited to low-order models, and although we found that BFI and $\mathrm{CMRO}_{2, \mathrm{i}}$ did not significantly change with time, the uncertainties associated with these measurements were relatively large. Thus, it is possible that $\mathrm{CBF}$ and oxygen metabolism were changing during the preoperative period, but the sensitivity of our measurements could have been too low to discern these changes. We note that application of simple steady-state models to our whole data set, relating OEF, CBF, and oxygen metabolism (on the basis of the mixed effects model results) are consistent within the measurement error bars. Higher frequency of data acquisition is needed to fit higher-order models to these preoperative variables and to decrease uncertainty, and these improvements will be necessary to begin to elicit an "optimal" timing of surgery with respect to cerebral hemodynamics. Additionally, the current study protocol did not permit for blood gas measurements at the same time as optical measurements, limiting analysis of the effect that changes in $\mathrm{Hgb}$ might have to the measured cerebral hemodynamics.

Another significant limitation in the present study is that it was conducted at a single site. Because preoperative care, specifically time from birth until surgery, varies between different institutions, the results presented in this report might be less applicable to other sites. Further investigation into different preoperative management strategies, operative strategies, and their effect on development of brain injury and trends in cerebral hemodynamics is necessary to further understand the relationship between clinical care and neurodevelopmental outcomes. The multicenter study described previously aims to accomplish this goal.

\section{CONCLUSIONS}

We investigated the preoperative trends in cerebral hemodynamics in neonates with TGA or HLHS awaiting surgery. We observed that cerebral tissue oxygenation decreases during the preoperative period in all patients, regardless of cardiac diagnosis. This decrease in oxygenation was associated with an increase in oxygen extraction, but not with a corresponding increase in CBF. The observed increase in oxygen demand without compensating oxygen delivery could lead to the previously reported increase in risk for white matter brain injury with longer time to surgery.

\section{Conflict of Interest Statement}

Authors have nothing to disclose with regard to commercial support.

We acknowledge invaluable assistance from Thomas Riley, Wesley Baker, Steven Schenkel, Michael Friedman, the staff of the cardiac intensive care unit at the Children's Hospital of Philadelphia, and most importantly, the patients and their families.

\section{References}

1. Hoffman JI, Kaplan S. The incidence of congenital heart disease. J Am Coll Cardiol. 2002;39:1890-900.

2. Graham EM, Zyblewski SC, Phillips JW, Shirali GS, Bradley SM, Forbus GA, et al. Comparison of Norwood shunt types: do the outcomes differ 6 years later? Ann Thorac Surg. 2010;90:31-5.

3. Bellinger D, Wypij D, Rivkin M, DeMaso D, Robertson R, Dunbar-Masterson C, et al. Adolescents with d-transposition of the great arteries corrected with the atrial switch procedure. Pediatr Cardiol. 2011;124:1361-9.

4. Marino B, Lipkin P, Newburger J, Peacock G, Gerdes M, Gaynor J, et al. Neurodevelopmental outcomes in children with congenital heart disease: evaluation and management: a scientific statement from the American Heart Association. Circulation. 2012;126:1143-72.

5. Shillingford A, Glanzman M, Ittenbach R, Clancy R, Gaynor J, Wernovsky G. Inattention, hyperactivity, and school performance in a population of school age children with complex congenital heart disease. Pediatrics. 2008;121: 759-67.

6. Mahle W, Tavani F, Zimmerman R, Nicolson S, Galli K, Ganor J, et al. An MRI study on neurological injury before and after congenital heart surgery. Circula tion. 2002;106:109-14. 
7. Imamura T, Ariga H, Kaneko M, Watanabe M, Shibukawa Y, Fukuda Y, et al. Neurodevelopmental outcomes of children with periventricular leukomalacia. Pediatr Neonatol. 2013;54:367-72.

8. Fawer CL, Diebold P, Calame A. Periventricular leucomalacia and neurodevelopmental outcome in preterm infants. Arch Dis Child. 1987;62:30-6.

9. Miller SP, Ferriero DM, Leonard C, Piecuch R, Glidden DV, Partridge C, et al. Early brain injury in premature newborns detected with magnetic resonance imaging is associated with adverse early neurodevelopmental outcome. J Pediatr. 2005;147:609-16.

10. Petit CJ, Rome JJ, Wernovsky G, Mason SE, Shera DM, Nicolson SC, et al. Preoperative brain injury in transposition of the great arteries is associated with oxygenation and time to surgery, not balloon atrial septostomy. Circulation. 2009;119:709-16.

11. Lynch JM, Buckley EM, Schwab PJ, McCarthy AL, Winters ME, Busch DR, et al. Time-to-surgery and pre-operative cerebral hemodynamics predict postoperative white matter injury in neonates with hypoplastic left heart syndrome. J Thorac Cardiovasc Surg. 2014;148:2181-8.

12. Durduran T, Choe R, Baker WB, Yodh AG. Diffuse optics for tissue monitoring and tomography. Rep Prog Phys. 2010;73:076701.

13. Goff DA, Buckley EM, Durduran T, Wang J, Licht DJ. Noninvasive cerebral perfusion imaging in high-risk neonates. Semin Perinatol. 2010;34: 46-56.

14. Buckley EM, Lynch JM, Goff DA, Schwab PJ, Baker WB, Durduran T, et al. Early post-operative changes in cerebral oxygen metabolism following neonatal cardiac surgery: effects of surgical duration. J Thorac Cardiovasc Surg. 2012; 145:196-205.

15. Durduran T, Zhou C, Buckley EM, Kim MN, Yu G, Choe R, et al. Optical measurement of cerebral hemodynamics and oxygen metabolism in neonates with congenital heart defects. J Biomed Opt. 2010;15:037004.

16. Jain V, Buckley EM, Licht DJ, Lynch JM, Schwab PJ, Naim MY, et al. Cerebral oxygen metabolism in neonates with congenital heart disease quantified by MRI and optics. J Cereb Blood Flow Metab. 2014;34:380-8.

17. Hueber DM, Franceschini MA, Ma HY, Zhang Q, Ballesteros JR, Fantini S, et al. Non-invasive and quantitiative near-infared haemoglobin spectrometry in the piglet brain during hypoxic stress, using a frequency-domain multidistance instrument. Phys Med Biol. 2001;46:41-62.

18. Kurth C, Thayer W. A multiwavelength frequency-domain near-infrared cerebral oximeter. Phys Med Biol. 1999;44:727.

19. Watzman HM, Kurth CD, Montenegro LM, Rome J, Steven JM, Nicolson SC. Arterial and venous contributions to near-infrared cerebral oximetry. Anesthesiology. 2000;93:947-53.

20. Culver JP, Durduran T, Furuya D, Cheung C, Greenberg JH, Yodh AG. Diffuse optical tomography of cerebral blood flow, oxygenation, and metabolism in rat during focal ischemia. J Cereb Blood Flow Metab. 2003;23: 911-24.

21. Boas DA, Yodh AG. Spatially varying dynamical properties of turbid media probed with diffusing temporal light correlation. J Opt Soc Am A Opt Image Sci Vis. 1997; 14:192-215.

22. Pine D, Weitz D, Chaikin PM, Herbolzheimer E. Diffusing wave spectroscopy. Phys Rev Lett. 1988;60:1134-7.

23. Weitz D, Pine D. Diffusing wave spectroscopy. In: Brown W, ed. Dynamic Light Scattering: The Method and Some Applications. Oxford: Oxford University Press; 1993:652-720.
24. Maret G, Wolf P. Multiple light scattering from disordered media. The effect of brownian motion of scatterers. Z Phys B - Condensed Matter. 1987;65:409-13.

25. Boas DA, Campbell LE, Yodh AG. Scattering and imaging with diffusing temporal field correlations. Phys Rev Lett. 1995;75:1855-8.

26. Buckley EM, Cook NM, Durduran T, Kim MN, Zhou C, Choe R, et al. Cerebral hemodynamics in preterm infants during positional intervention measured with diffuse correlation spectroscopy and transcranial Doppler ultrasound. Opt Express. 2009; 17:12571-81.

27. Buckley EM, Hance D, Pawlowski T, Lynch JM, Wilson FB, Mesquita RC, et al. Validation of diffuse correlation spectroscopic measurement of cerebral blood flow using phase-encoded velocity mapping magnetic resonance imaging. J Biomed Opt. 2012;17:037007.

28. Diop M, Migueis M, Lee T, Lawrence KS. Comparison of time-resolved and continuous-wave near-infrared techniques for measuring cerebral blood flow in piglets. J Biomed Opt. 2010;15:057004.

29. Kim MN, Durduran T, Frangos S, Edlow BL, Buckley EM, Moss HE, et al. Noninvasive measurement of cerebral blood flow and blood oxygenation using near-infrared and diffuse correlation spectroscopies in critically brain-injured adults. Neurocrit Care. 2010;12:173-80.

30. Zhou C, Eucker SA, Durduran T, Yu G, Ralston J, Friess SH, et al. Diffuse optical monitoring of hemodynamic changes in piglet brain with closed head injury. $J$ Biomed Opt. 2009;14:034015.

31. Childs AM, Ramenghi LA, Cornete L, Tanner SF, Arthur RJ, Martinez D, et al. Cerebral maturation in premature infants: quantitative assessment using MR imaging. Am J Neuroradiol. 2001;22:1577-82.

32. Licht DJ, Shera DM, Clancy R, Wernovsky G, Montenegro LM, Nicolson SC, et al. Brain maturation is delayed in infants with complex congenital heart defects. J Thorac Cardiovasc Surg. 2009;137:529-36.

33. Franceschini MA, Thaker S, Themelis G, Krishnamoorthy KK, Bortfeld H, Diamond SG, et al. Assessment of infant brain development with frequencydomain near-infrared spectroscopy. Pediatr Res. 2007;61:546-51.

34. Roche-Labarbe N, Fenoglio A, Aggarwal A, Dehaes M, Carp SA, Franceschini MA, et al. Near-infrared spectroscopy assessment of cerebral oxygen metabolism in developing premature brain. J Cereb Blood Flow Metab. 2012;32:481-8.

35. Szwast A, Tian Z, McCann M, Soffer D, Rychik J. Comparitive analysis of cerebrovascular resistance in fetuses with single-ventricle congenital heart disease. Ultrasound Obstet Gynecol. 2012;40:62-7.

36. Kaltman JR, Di H, Tian Z, Rychik J. Impact of congenital heart disease on cerebrovascular blood flow dynamics inthe fetus. Ultrasound Obstet Gynecol. 2005; 25:32-6.

37. Sun L, Macgown C, Sled J, Yoo S, Manlhoit C, Porayette P, et al. Reduced fetal cerebral oxygen consumption is associated with smaller brain size in fetuses with congenital heart disease. Circulation. 2015;131:1313-23.

38. Rudolph AM. The changes in the circulation after birth. Their importance in congenital heart disease. Circulation. 1970;41:343-59.

39. Lynch JM, Licht DJ. First things first: the importance of the preoperative period for neurolic outcomes in hypoplastic left heart syndrome. J Thorac Cardiovasc Surg. 2016;151:1367-8.

Key Words: CHD, cerebral blood flow, neonate, timing of surgery 